\title{
Characterization of Surface Oxide Layers on Black-Colored Titanium
}

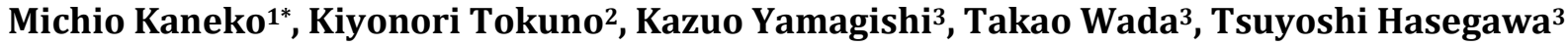 \\ ${ }^{1}$ Steel Research Laboratories, Nippon Steel and Sumitomo Metal Corporation, Shintomi Futtsu, Japan \\ ${ }^{2}$ Head Office, Nippon Steel and Sumitomo Metal Corporation, Tokyo, Japan \\ ${ }^{3}$ Toyo Rikagaku Kenkyusho Corporation, Tsubame, Niigata, Japan \\ Email: ^kaneko.h8m.michio@jp.nssmc.com
}

How to cite this paper: Kaneko, M., Tokuno, K., Yamagishi, K., Wada, T. and Hasegawa, T. (2018) Characterization of Surface Oxide Layers on Black-Colored Titanium. Journal of Surface Engineered Materials and Advanced Technology, 8, 71-82. https://doi.org/10.4236/jsemat.2018.84007

Received: July 2, 2018

Accepted: September 3, 2018

Published: September 6, 2018

Copyright $\odot 2018$ by authors and Scientific Research Publishing Inc. This work is licensed under the Creative Commons Attribution International License (CC BY 4.0).

http://creativecommons.org/licenses/by/4.0/

\begin{abstract}
Black-colored titanium was obtained by anodic oxidation of a commercially pure grade- 1 titanium sheet in a $0.06 \mathrm{M} \mathrm{NH}_{4} \mathrm{NO}_{3}$ solution, followed by heat treatment at $773 \mathrm{~K}$ for $1 \mathrm{~h}$ in a vacuum furnace. The resulting oxide layer on the titanium substrate was examined by X-ray photoelectron spectroscopy, $\mathrm{X}$-ray diffraction, glow discharge spectroscopy, and scanning electron microscopy. It was found that the oxide layer on the black-colored titanium sheet was several micrometers thick and mainly consisted of rutile $\mathrm{TiO}_{2}$ exhibiting a sponge like nanoporous structure. It is considered that the black-colored appearance of the titanium sheet is due to the sponge like nanoporous structure of the oxide layer absorbing the incident light. The photocatalytic activity of the black-colored titanium sheet was examined by observing the decomposition of a methylene blue $\left(\mathrm{MB}, \mathrm{C}_{16} \mathrm{H}_{18} \mathrm{~N}_{3} \mathrm{SCl}\right)$ solution under ultraviolet irradiation due to the existence of rutile $\mathrm{TiO}_{2}$. The sheet also exhibited photocatalytic activity under visible light irradiation. It is believed that the photocatalytic response upon irradiation with white light is due to carbon doping of the titanium oxide layer on the titanium substrate.
\end{abstract}

\section{Keywords}

Titanium, Titanium Oxide, Titanium Dioxide, Rutile, Photocatalyst, Visible Light Response, Nanoporous Structure

\section{Introduction}

Titanium exhibits good corrosion resistance due to the highly protective titanium oxide layer formed on its surface. Titanium oxides have another important feature: photocatalytic activity under irradiation by ultraviolet (UV) light [1]. 
The anodic oxidation of titanium in an aqueous solution is a well-known method for producing titanium oxide layers on titanium substrates. Many studies have been conducted on the fabrication of anodized-titanium layers with enhanced photocatalytic activity on titanium substrates [2]. Onoda et al. [3] reported that the anodization of a pre-nitrated titanium substrate in a mixed electrolyte composed of $\mathrm{H}_{2} \mathrm{SO}_{4}, \mathrm{H}_{3} \mathrm{PO}_{4}$, and $\mathrm{H}_{2} \mathrm{O}_{2}$ resulted in enhanced photocatalytic activity. Ohtsu et al. [4] investigated the effects of anions in various ammonium salt electrolytes such as $\left(\mathrm{NH}_{4}\right)_{2} \mathrm{SO}_{4},\left(\mathrm{NH}_{4}\right)_{2} \mathrm{PO}_{4}$, and $\left(\mathrm{NH}_{4}\right)_{2} \mathrm{O}_{5} \mathrm{~B}_{2} \mathrm{O}_{3}$ solutions, and it was concluded that $\mathrm{S}, \mathrm{P}$, and $\mathrm{B}$ were incorporated into titanium oxide layers on the titanium substrates, which affected their photocatalytic activity. Concerning the visible light response, Mizukoshi et al. [5] conducted a study on sulfur-doped rutile titanium dioxide photocatalysts. Ohtsu et al. [6] reported that a visible-light-responsive titanium dioxide layer was fabricated by anodizing a titanium sheet in aqueous nitric acid solutions, followed by heat treatment.

The authors [7] also conducted studies to develop an anodized titanium sheet with enhanced photocatalytic activity. An anodized titanium sheet that showed high photocatalytic activity under UV irradiation was fabricated by the anodic oxidation of a commercially pure (CP) titanium sheet in a $0.06 \mathrm{M} \mathrm{NH}_{4} \mathrm{NO}_{3}$ aqueous solution, followed by heat treatment at $803 \mathrm{~K}$ for $1 \mathrm{~h}$ in air. The anodized titanium sheet also exhibited photocatalytic activity when irradiated with visible light. It was concluded that the enhanced photocatalytic activity under UV irradiation could be attributed to the formation of anatase titanium dioxide and an increase in the surface area. The visible light response of the anodized titanium sheet was believed to be due to $\mathrm{C}$ and $\mathrm{N}$ doping in the anatase titanium dioxide layer.

On the basis of our previous studies described above, we investigated the effect of heat treatment in a vacuum furnace on the characteristics of anodized titanium sheets. We observed that the color of the anodized titanium sheet turned black after heat treatment in the vacuum furnace. Thus, X-ray photoelectron spectroscopy (XPS), X-ray diffraction (XRD), glow discharge spectroscopy (GDS), and scanning electron microscopy (SEM) analyses were conducted to characterize the black-colored titanium sheet. The photocatalytic activity of the black-colored titanium sheet was also examined by observing the decomposition of a methylene blue (MB) solution by irradiation with UV or visible light.

\section{Experimental Procedure}

\subsection{Material Preparation}

CP grade-1 titanium sheets cold rolled to a thickness of $0.4 \mathrm{~mm}$ were heat treated in a vacuum annealing furnace. The holding temperature and time were $873 \mathrm{~K}$ and $6 \mathrm{~h}$, respectively. The average heating rate was approximately $100 \mathrm{~K} / \mathrm{h}$, and the cooling rate was nearly $50 \mathrm{~K} / \mathrm{h}$. The concentrations of impurity elements in the CP titanium sheets are shown in Table 1.

The titanium sheets were rinsed in acetone and immersed in a $0.06 \mathrm{M} \mathrm{NH}_{4} \mathrm{NO}_{3}$ 
Table 1. Concentration of impurity elements in CP grade-1 Ti sheet (mass \%).

\begin{tabular}{ccccc}
\hline $\mathrm{O}$ & $\mathrm{H}$ & $\mathrm{C}$ & $\mathrm{Fe}$ & $\mathrm{N}$ \\
\hline 0.0473 & 0.0022 & 0.008 & 0.025 & 0.004 \\
\hline
\end{tabular}

solution for anodic oxidation. The anodic oxidation was conducted at $80 \mathrm{~V}$ for $120 \mathrm{~s}$ at $298 \mathrm{~K}$. After anodization, the sheets were rinsed in distilled water and air-dried. After these treatments, the sheets were heated to $773 \mathrm{~K}$ in a vacuum furnace for $1 \mathrm{~h}$, held at a pressure of $1 \times 10^{-3}$ Torr, and subsequently furnace cooled. The sheets were then cut into $25 \mathrm{~mm} \times 25 \mathrm{~mm} \times 0.4 \mathrm{~mm}$ and $15 \mathrm{~mm} \times$ $25 \mathrm{~mm} \times 0.4 \mathrm{~mm}$ samples for various analyses and photocatalytic activity measurements, respectively.

\subsection{Characterization of the Titanium Sheet after Anodization and Vacuum Heat Treatment}

The color of the specimen was quantitatively evaluated by colorimetry using $\mathrm{L}^{*}, \mathrm{a}^{*}$ and $\mathrm{b}^{*}$ coordinates. $\mathrm{L}^{*}, \mathrm{a}^{*}$ and $\mathrm{b}^{*}$ are darkness-brightness, green-red and blue-yellow, respectively [8]. In addition, ultraviolet-visible-near infrared (UV-Vis-NIR) spectroscopy was conducted to measure the reflection ratio (\%) of the titanium specimen at wavelengths from $250 \mathrm{~nm}$ to $2500 \mathrm{~nm}$. The incident angle of the UV-Vis-NIR light to the sample surface was $8^{\circ}$. XPS was conducted using monochromatized Al Karadiation (1486.6 eV) combined with Ar ion sputtering to investigate the chemical states of $\mathrm{Ti}$ and $\mathrm{C}$ in the anodized titanium oxide layer on the titaniumsubstrate. The anodic oxide layer was also analyzed by XRD to investigate its structure. For the XRD measurements, the incident angle of the X-ray beam to the sample surface was $1^{\circ}$. The surface and cross-sectional morphology of the titanium sample after anodization and vacuum heat treatment was observed by SEM. GDS was conducted to measure the thickness and elemental content of the whole oxide layer.

\subsection{Photocatalytic Activity Test}

Photocatalytic activity was measured using a methylene blue (MB) solution. A regent grade methylene blue trihydrate was dissolved into distilled water to make $3.13 \times 10^{-5} \mathrm{M} \mathrm{MB}$ solution. Test samples of the titanium sheet before and after anodization and vacuum heat treatment $-15 \mathrm{~mm} \times 25 \mathrm{~mm} \times 0.4 \mathrm{~mm}$ in size-were separately dipped in $4 \mathrm{~cm}^{3}$ of a $3.13 \times 10^{-5} \mathrm{M} \mathrm{MB}$ solution at $298 \mathrm{~K}$ and illuminated with a black-light UV source for $1800 \mathrm{~s}$. The intensity of the black light at $365 \mathrm{~nm}$ was $1010 \mu \mathrm{W} / \mathrm{cm}^{2}$. After the irradiation with black light, the absorbance of the MB solution at $664 \mathrm{~nm}$ was measured by absorption spectrophotometry to evaluate the decomposition of MB by photocatalytic reaction.

In addition to black-light irradiation, white light-emitting diode (LED) irradiation was conducted to evaluate the visible light response of the titanium sheet after anodization and vacuum heat treatment. The intensity of the white LED illumination was 47,000 lx. After irradiation with white LED light, the absorbance 
of the MB solution at $664 \mathrm{~nm}$ was measured by absorption spectrophotometry.

\section{Experimental Results and Discussion}

Figure 1 shows three titanium sheets: 1) titanium sheet without anodization and heat treatment, 2) titanium sheet anodized in a $0.06 \mathrm{M} \mathrm{NH}_{4} \mathrm{NO}_{3}$ solution, and 3) titanium sheet after anodization and vacuum heat treatment. Although the color of the anodized specimen was gray, it turned black after heat treatment in the low-vacuum furnace. Table 2 shows measured $L^{*}, a^{*}$ and $b^{*}$ values for samples (1) and (3) shown in Figure 1. As shown in Table 2, the value of $\mathrm{L}^{*}$ decreased significantly and both $a^{*}$ and $b^{*}$ decreased to near zero. These changes in $L^{*}, a^{*}$, and $b^{*}$ correspond exactly to the change in color from metallic silver to black. Figure 2 shows UV-Vis-NIR spectroscopy results from the black-colored titanium sheet. It was found that incident light of wavelengths from $200 \mathrm{~nm}$ to 2500 $\mathrm{nm}$ was effectively absorbed by the black-colored titanium sheet.

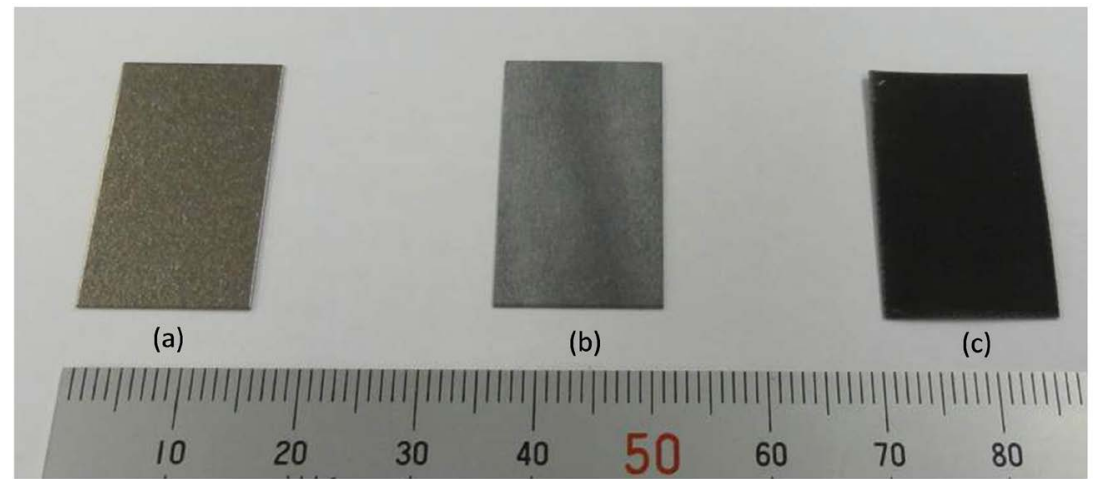

Figure 1. Outward appearance of titanium sheets: (a) Titanium sheet without anodization and heat treatment, (b) Titanium sheet anodized in a $0.06 \mathrm{M} \mathrm{NH}_{4} \mathrm{NO}_{3}$ solution, and (c) Titanium sheet anodized and heat-treated in a low-vacuum furnace.

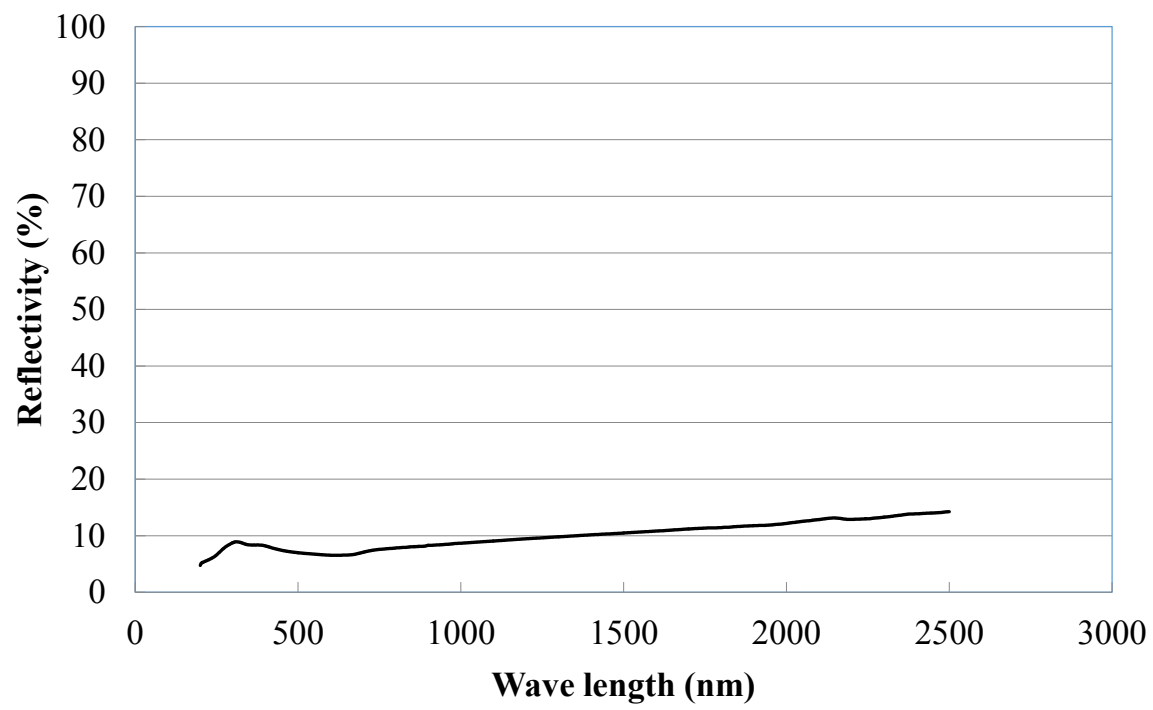

Figure 2. UV-Vis-NIR reflectivity of the titanium sheet after anodization and low-vacuum heat treatment. 
Table 2. $L^{*}, a^{*}$, and $b^{*}$ values of the two samples shown in Figure 1(a) and Figure 1(c).

\begin{tabular}{cccc}
\hline Samples & $\mathrm{L}^{*}$ & $\mathrm{a}^{*}$ & $\mathrm{~b}^{*}$ \\
\hline Sample (a) in Figure 1 & 68.26 & 1.41 & 5.06 \\
Sample (c) in Figure 1 & 28.91 & 0.50 & 0.22 \\
\hline
\end{tabular}

It has been reported that $\mathrm{Ti}_{\mathrm{n}} \mathrm{O}_{(2 \mathrm{n}-1)}(\mathrm{n}=2-4)$ exhibits a black color [9]. Additionally, H. Matsunaga et al. [10] investigated the effect of anodization, followed by vacuum heat treatment on the color of a titanium sheet, in order to fabricate black-colored titanium sheets by forming low-valence titanium oxide, such as $\mathrm{TiO}$ or $\mathrm{Ti}_{2} \mathrm{O}_{3}$. As a result, a relatively black-colored titanium sheet was obtained by anodic oxidation at $150 \mathrm{~V}$ in a mixed solution of $0.3 \mathrm{M} \mathrm{H}_{3} \mathrm{PO}_{4}, 0.4 \mathrm{M} \mathrm{H}_{2} \mathrm{SO}_{4}$, and $0.3 \mathrm{M} \mathrm{H}_{2} \mathrm{O}_{2}$ followed by vacuum heat treatment at $673 \mathrm{~K}$ for $8 \mathrm{~h}$ at a pressure of $1 \times 10^{-3}$ Torr; however, there is no report on whether low-valence titanium oxides were formed or not. In addition, $\mathrm{H}$. Jun-xiang et al. reported that plasma electrolytic oxidation of Ti-6Al-4V alloy or pure titanium was carried out and the black appearance can be attributed to the presence of $\mathrm{Ti}^{2+}$ and $\mathrm{Ti}^{3+}[11]$.

The vacuum pressure used during the heat treatments in this study was lower than that used by Matsunaga et al.; therefore, the formation of low-valence titanium oxides is plausible. Thus, XPS analysis was carried out to investigate the valence state of titanium oxide from the outersurface to a depth of $1047.1 \mathrm{~nm}$. The obtained results are shown in Figure 3. Clearly, $\mathrm{TiO}_{2}$ was formed on the surface layer of the titanium substrate. Low-valence Ti peaks were observed inside the titanium oxide layer; however, $\mathrm{Ti}^{4+}$ might be reduced during Arion sputtering.

Therefore, XRD measurements were conducted, and the obtained results are shown in Figure 4. Other than the diffraction peaks from metallic titanium, the strongest diffraction peaks are attributable to rutile $\mathrm{TiO}_{2}$, and weak peaks from anatase $\mathrm{TiO}_{2}$ were detected. No peaks from low-valance titanium oxides were observed. This clearly indicates that the black-colored appearance is not due to the formation of low-valence titanium oxides.

Consequently, the surface and cross-sectional morphology of the black-colored titanium sheet was examined by SEM. Figure 4 shows SEM images of the surface of the black-colored titanium sheet. As shown in Figure 5, the surface is quite rough with many holes as small as a few tens of nanometers. Figure 6 shows cross-sectional SEM images of the black-colored titanium sheet. As shown in Figure 6, the thickness of the oxide layer is several micrometers and the layer has the small holes with their width of several tens nanometers and several hundred nanometers in length. Based on these observations, it is considered that the black color induced by anodization and subsequent vacuum heat treatment is attributable to a sponge like nanostructure that might strongly absorb visible light.

Next, the photocatalytic activity of the black-colored titanium sheet was examined by observing the decomposition of MB under black-light irradiation. 


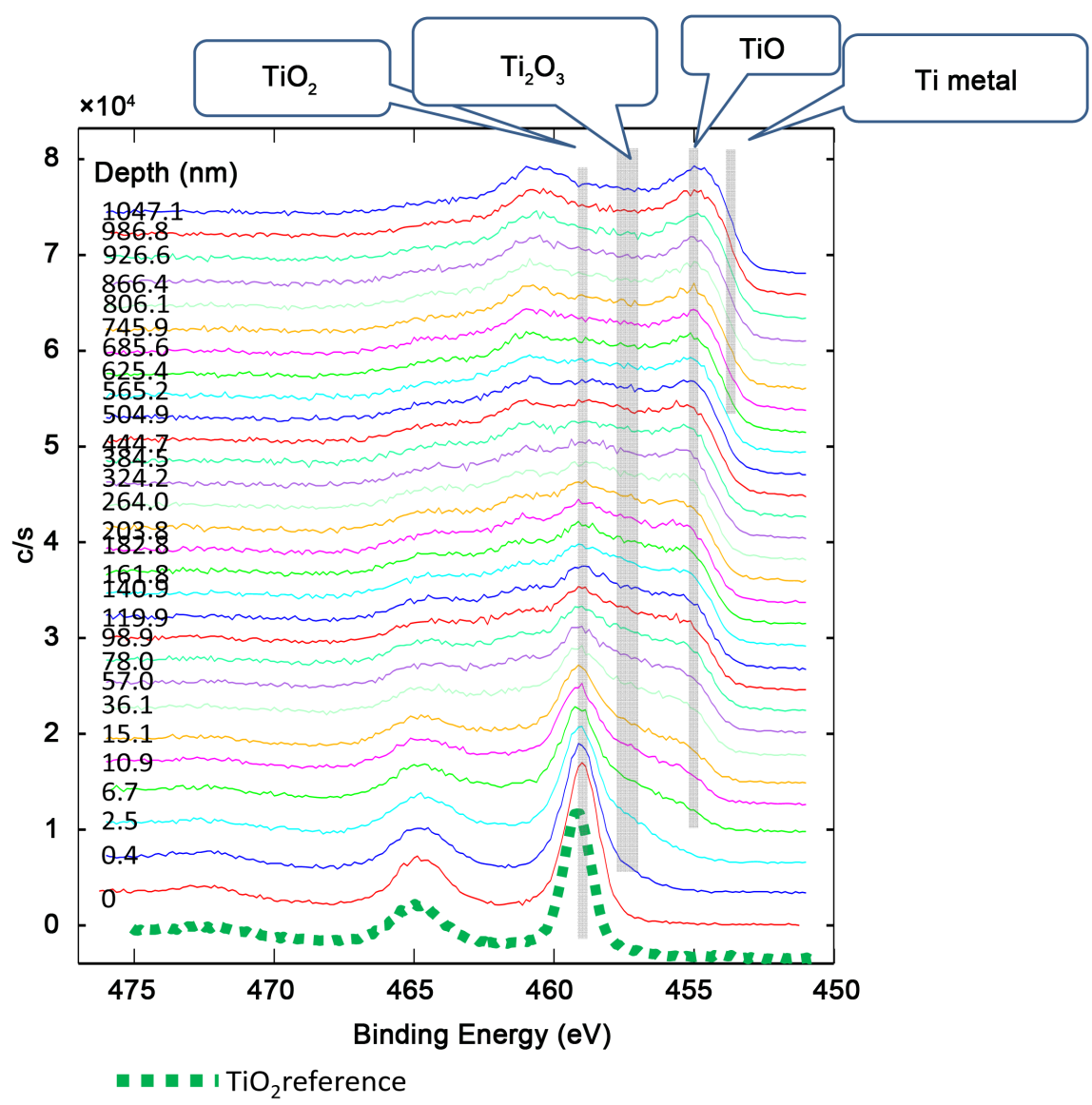

Figure 3. XPS analysis of Ti (1 s) from surface to interior of the oxide layer formed on the titanium sheet after anodization and low-vacuum heat treatment.

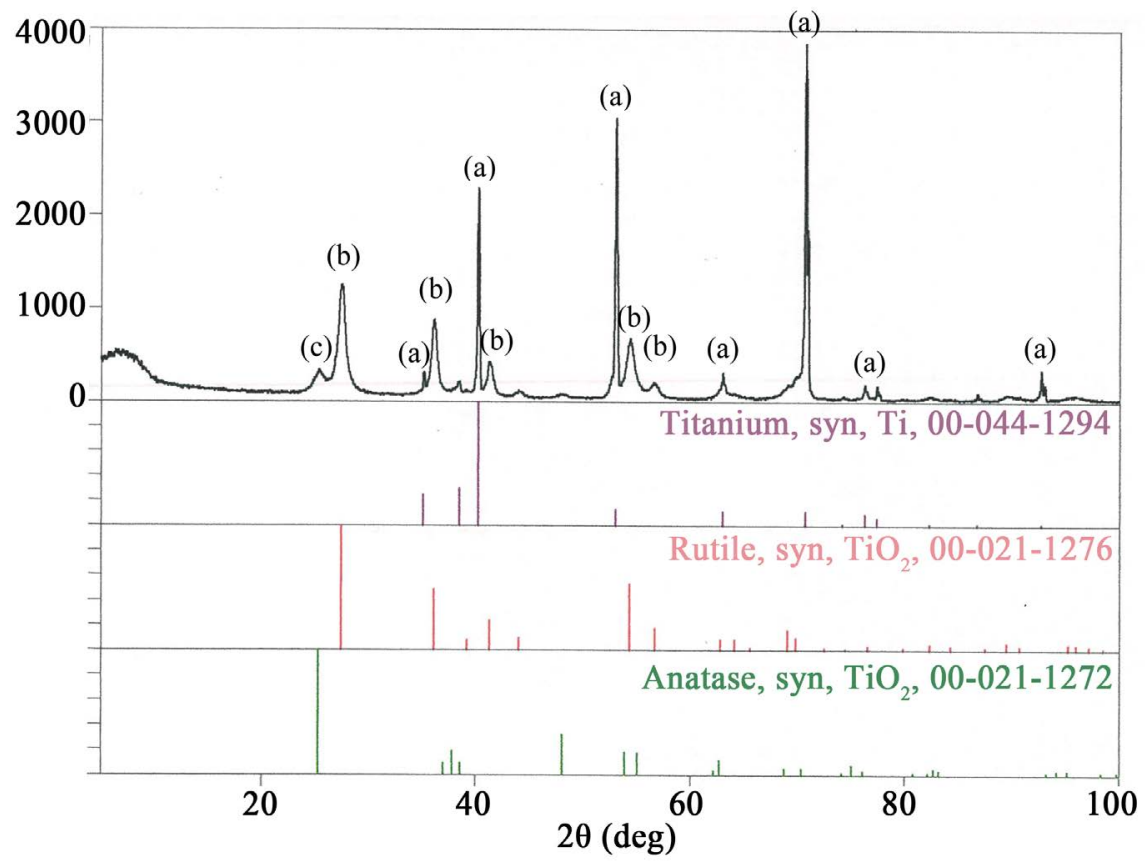

Figure 4. XRD patterns of titanium sheet after anodization and low-vacuum heat treatment, (a) Metallic titanium; (b) Rutile $\mathrm{TiO}_{2}$; and (c) Anatase $\mathrm{TiO}_{2}$. 

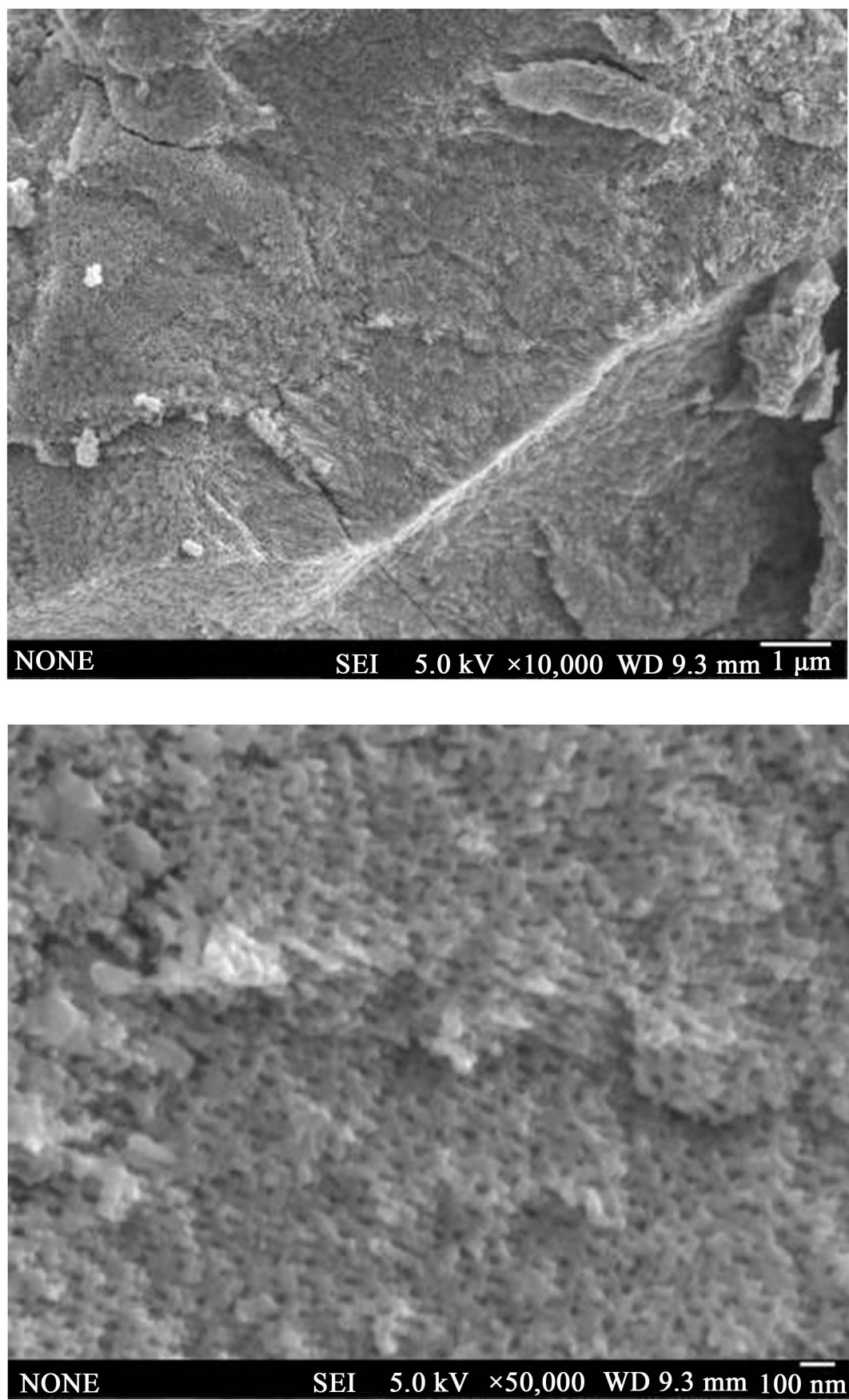

Figure 5. SEM images of the surface of titanium sheet after anodization and low-vacuum heat treatment.

Figure 7 shows the photocatalytic-activity test results under the black-light irradiation. The absorbance of the anodized and vacuum heat-treated titanium sheet was almost half that of the untreated titanium sheet due to the decomposition of $\mathrm{MB}$ under black-light irradiation. As shown in Figure 4, rutile $\mathrm{TiO}_{2}$ is the main component of the titanium oxide layer. The photocatalytic activity of the black-colored titanium sheet was therefore considered to be due to the presence of rutile $\mathrm{TiO}_{2}$. 

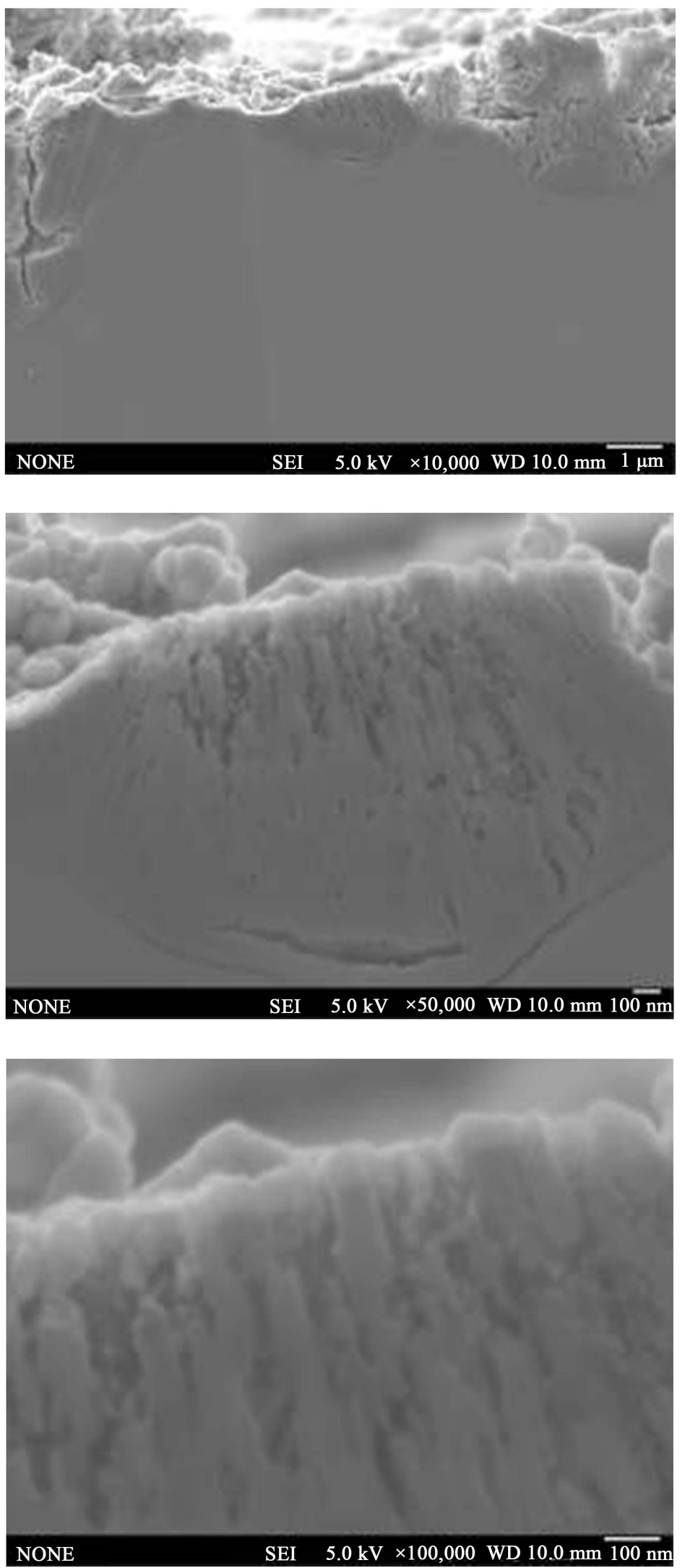

Figure 6. Cross-sectional SEM images of titanium sheet after anodization and low-vacuum heat treatment. 
In addition to the black-light irradiation, the photocatalytic activity under visible light irradiation was also examined. As shown in Figure 8, the black-colored titanium sheet exhibited photocatalytic activity under irradiation with white LED light. However, both rutile and anatase $\mathrm{TiO}_{2}$ do not show photocatalytic activity when irradiated with visible light. Therefore, impurity elements, specifically carbon and nitrogen, inside the titanium oxide layer on the titanium substrate were examined by GDS. The results of the GDS analysis are shown in Figure 9. The concentration of nitrogen was very low. A large amount of carbon was observed in the titanium oxide layer; however, the state of the carbon in the titanium oxide layer was not clarified by GDS. The chemical state of carbon in

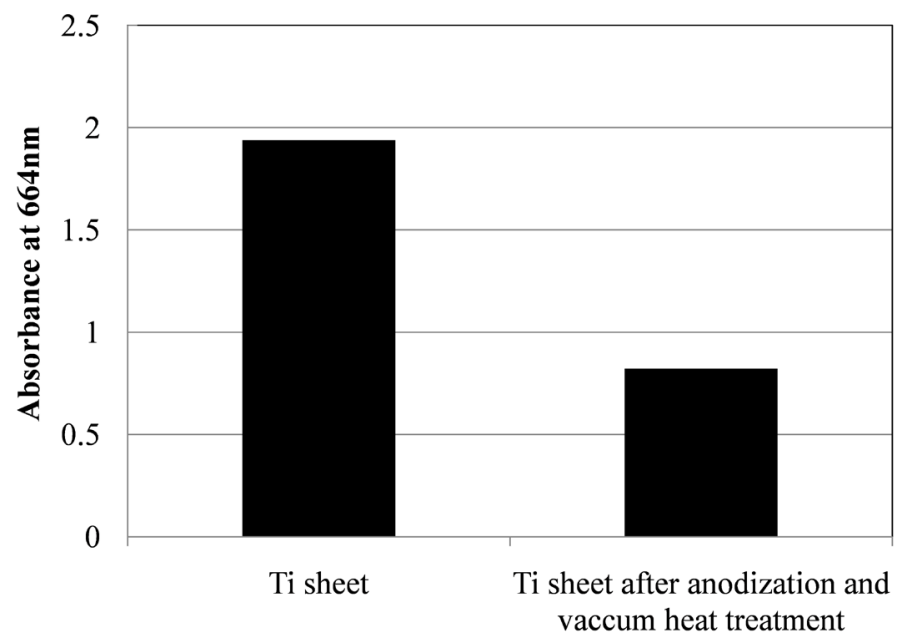

Figure 7. Photocatalytic activity test results under black-light irradiation.

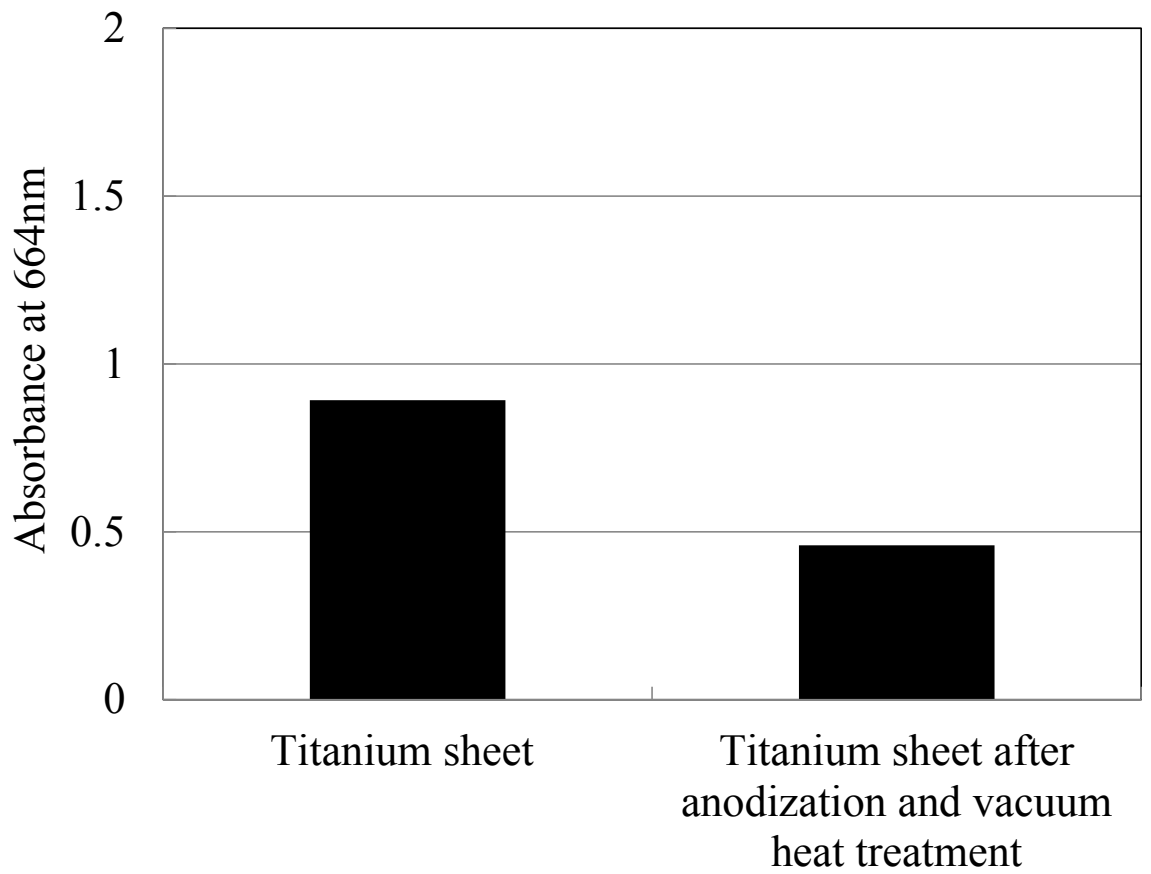

Figure 8. Photocatalytic activity test results under white LED-light irradiation. 
the titanium oxide layer was therefore examined by XPS.

Figure 10 shows the chemical state of carbon in the titanium oxide layer as determined by XPS. From the data in Figure $10,(\mathrm{C}-\mathrm{H})_{\mathrm{n}}$ bonding was observed,

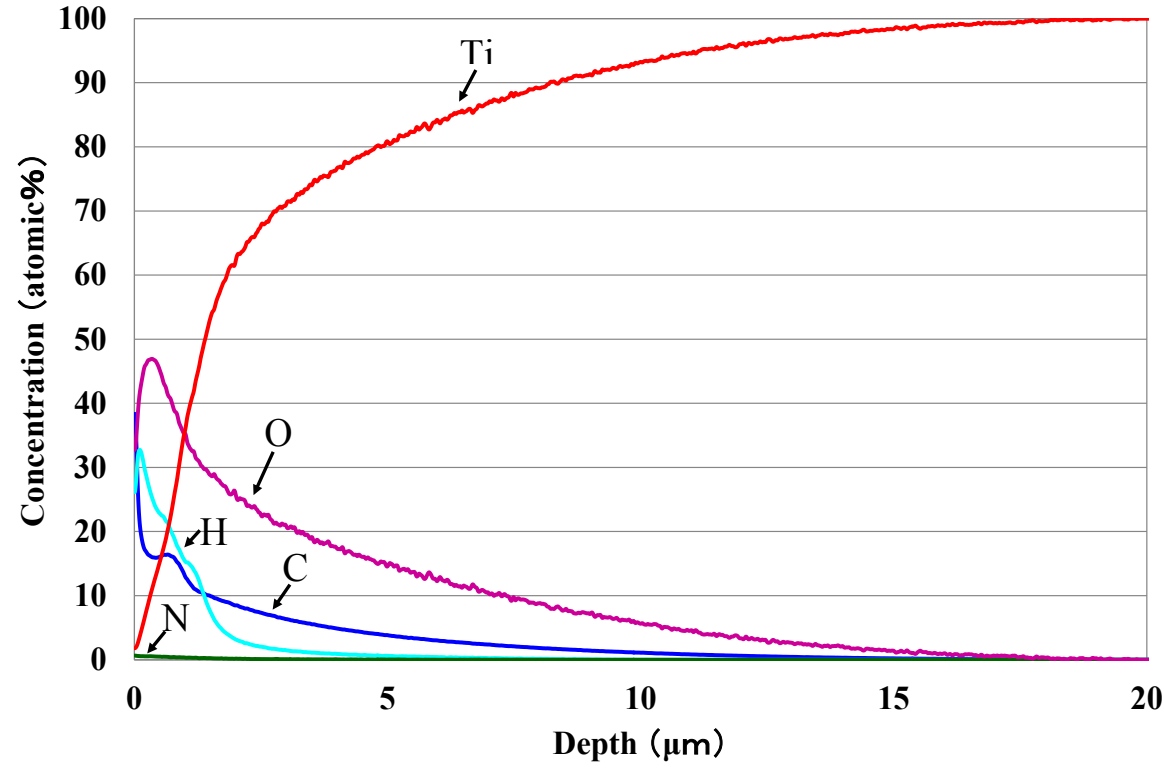

Figure 9. GDS analysis of the titanium sheet after anodization and low-vacuum heat treatment.

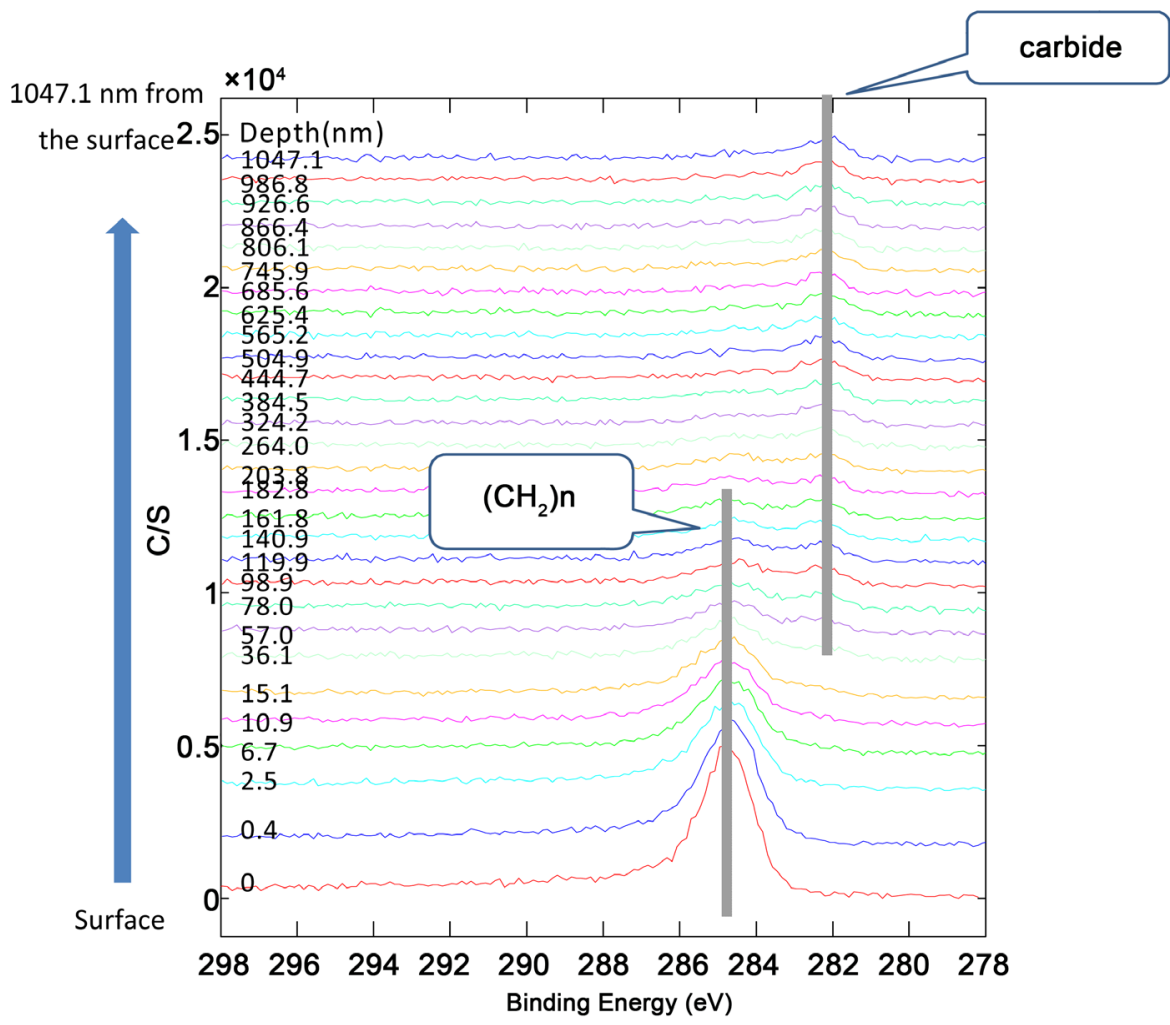

Figure 10. XPS analysis of C (1 s) from surface to interior of the oxide layer formed on the titanium sheet after anodization and low-vacuum heat treatment. 
which was presumably caused by contamination; however, a peak other than $(\mathrm{C}-\mathrm{H})_{\mathrm{n}}$ was also observed, which indicates the presence of carbides deeper than $57.0 \mathrm{~nm}$. As R. Asahi et al. reported the doping of carbon and nitrogen into titanium oxide could induce a visible light response [12]. Thus, it is believed that carbon doping of the titanium oxide layer induced a visible light response. The mechanism of carbon doping into the titanium oxide layer has been described elsewhere [7].

\section{Conclusion}

A black-colored titanium sheet was obtained by the anodic oxidation of CP grade- 1 titanium sheet in a $0.06 \mathrm{M} \mathrm{NH}_{4} \mathrm{NO}_{3}$ solution followed by heat treatment at $773 \mathrm{~K}$ for $1 \mathrm{~h}$ in a low-vacuum furnace. The resulting oxide layer on the titanium substrate was examined by XPS, XRD, GDS, and SEM. It was found that the thickness of the oxide layer was more than a few micrometers, and mainly consisted of rutile $\mathrm{TiO}_{2}$ with a sponge-like nanoporous structure. It is considered that the black-colored appearance of the titanium sheet is due to the sponge likenanoporous structure of the titanium oxide layer. The photocatalytic activity of the black-colored titanium sheet was examined by monitoring the decomposition of a methylene blue (MB) solution under UV irradiation due to the existence of rutile $\mathrm{TiO}_{2}$. The sheet also exhibited photocatalytic activity under visible light irradiation. It is strongly suggested that the photocatalytic response under irradiation with white LED light is due to carbon doping in the titanium oxide layer on the titanium substrate.

\section{Conflicts of Interest}

The authors declare no conflicts of interest regarding the publication of this paper.

\section{References}

[1] Ito, T., Hayata, K. and Sugimoto, T. (2006) Surface Modification of Titanium Alloys by Coating with Anatase-Type $\mathrm{TiO}_{2}$. Journal of Japan Institute of Metals and Materials, 70, 936-939.

[2] Tuncay, D., Metin, Y., Erdal, C. and Selim, D. (2017) The Effects of Growth Conditions on the Surface Properties and Photocatalytic Activities of Anatase $\mathrm{TiO}_{2}$ Films Prepared via Electrochemical Anodizing and Annealing Methods. Journal of Porous Materials, 24, 1535. https://doi.org/10.1007/s10934-017-0393-2

[3] Onoda, K. and Yoshikawa, S. (2007) Effect of Electrolysis Conditions on Photocatalytic Activities of the Anodized $\mathrm{TiO}_{2}$ Films. Journal of Solid State Chemistry, 180, 3425 .

[4] Ohtsu, N., Komiyama, S. and Kodama, K. (2013) Effect of Electrolytes on Anodic Oxidation of Titanium for Fabricating Titanium Dioxide Photocatalyst. Thin Solid Films, 534, 70.

[5] Mizukoshi, Y., Ohtsu, N., Semboshi, S. and Masahashi, N. (2009) Effect of Electrolytes on Anodic Oxidation of Titanium for FabricatingTitanium Dioxide Photocatalyst. Applied Catalysis, B91, 152.

[6] Ohtsu, N., Kanno, H., Komoyama, S., Mizukoshi, Y. and Masahashi, N. (2013) Fabrication of Visible-Light-Responsive Titanium Dioxide Layer on Titanium Using 
Abodic Oxidation in Nitric Acid. Applied Surface Science, 270, 513.

[7] kaneko, M., Tokuno, K., Yamagishi, K., Wada, T. and Hasegawa, T. (2014) Photocatalytic Activity of Anodized Titanium Sheets under Ultra-Violet and Visible Light Irradiation. Journal of Surface Engineered Materials and Advanced Technology, 4, 369. https://doi.org/10.4236/jsemat.2014.46041

[8] Japanese Industrial Standard 8781-4 (2013).

[9] Ito, S., Ihara, T., Miura, Y. and Mkiboku (1987) Preparation of Black Pigment of Lower Titanium Oxide System. Proceeding of The $4^{\text {th }}$ International Conference of Plasma Chemistry and Technology, San Diego, CA, USA.

[10] Matsunaga, H., Hiromichi, M., Haneda, T. and Ito, S. (1990) Effect of Vacuum Heat Treatment on Color of Anodized Titanium Oxide Film. The $82^{\text {nd }}$ Conference, The Surface Finishing Society of Japan, 18C-26, 230.

[11] Han, J.-X., Cheng, X.-L., Tu, W.-B., Zhan, T.-Y. and Cheng, L.-L. (2018) The Black and White Coatings on Ti-6Al-4V Alloy or Pure Titanium by Plasma Electrolytic Oxidation in Concentrated Silicate Electrolyte. Applied Surface Science, 428, 684.

[12] Asahi, R., Morikawa, T., Ohwaki, T., Aoki, K. and Taga, Y. (2001) Visible-Light Photocatalysis in Nitrogen-Doped Titanium Oxides. Science, 293, 269.

https://doi.org/10.1126/science.1061051 